\title{
Hairy Polyp of the Supratonsillar Fossa Causing Intermittent Airway Obstruction
}

\author{
Onur İsmi ${ }^{1}$ Kemal Görür ${ }^{2}$ Rabia Bozdoğan Arpacı ${ }^{3}$ \\ ${ }^{1}$ Assistant Professor; Department of Otorhinolaryngology, Faculty of \\ Medicine, University of Mersin \\ 2 Professor; Department of Otorhinolaryngology, Faculty of Medicine, \\ University of Mersin \\ ${ }^{3}$ Assistant Professor; Department of Pathology, Faculty of Medicine, \\ University of Mersin \\ ${ }^{4}$ Associate Professor; Department of Otorhinolaryngology, Faculty of \\ Medicine, University of Mersin
}

Int Arch Otorhinolaryngol 2015;19:90-92.

\begin{abstract}
Address for correspondence Onur İsmi, MD, Department of Otorhinolaryngology, Mersin University, Mersin Üniversitesi Hastanesi çiftlikköy kampüsü kulak burun boğaz a.d, Mersin 33190, Turkey (e-mail: dronurismi@gmail.com).
\end{abstract}

\begin{abstract}
Introduction Dermoids frequently called "hairy polyps" and their nature have not been completely clarified.

Objectives To discuss the unusual presentation, symptoms, incidence, histology, and perioperative management of hairy polyps in the light of a case and current literature. Resumed Report A 3-year-old boy presented with intermittent respiratory distress since birth. Oropharyngeal examination revealed a nasopharyngeal mass originating

Keywords

- hairy polyp

- airway obstruction

- oropharynx

- nasopharynx from the supratonsillar fossa. The mass was so mobile that it moved between the oropharynx and the nasopharynx during swallowing. The radiologic and pathologic examinations confirmed the mass as a hairy polyp.

Conclusion In a pediatric age group with airway obstruction, hairy polyps of the oropharyngeal region must also be included in the differential diagnosis.
\end{abstract}

\section{Introduction}

Dermoid cysts are rare and benign teratomatous congenital lesions. Hairy polyp (HP) is a developmental malformation that was described by Brown Kelly in $1918 .^{1}$ They are most commonly a type of dermoid. ${ }^{2}$ They are frequently located in the orbit, nasal dorsum, floor of the mouth, infratemporal fossa, nasopharynx, oropharynx, and anterior and lateral side of the neck. ${ }^{3-8}$ They can also originate from the eustachian tube. ${ }^{1,9}$ Only 1 to $7 \%$ of all dermoid cysts affect the head and neck region; $23 \%$ of those are seen in the floor of the mouth. ${ }^{10,11}$ When dermoids and epidermoids are located in the head and neck region, they are the most congenital midline nasal masses. ${ }^{12}$ Dermoid cysts, like teratomas, consist of embryonic germ layers. Teratomas contain all three germ layers including ectoderm, mesoderm, and endoderm, and dermoid cysts contain only mesoderm and ectoderm. ${ }^{13}$ Mesodermal elements, which include hair follicles and sweat glands within the wall of the dermoid cysts, differentiate it from simple epidermoid cysts. ${ }^{14,15}$ Although both HPs and dermoid cysts contain ectodermal and mesodermal germ layers histologically, dermoid cysts contain ectodermal inclusion cysts in their mesodermal layer, which is lacking in HPs. ${ }^{12}$

The purpose of this report is to present and discuss a rare case of oropharyngeal HP resulting in an upper airway obstruction during crying.

\section{Review of the Literature with Differential Diagnosis}

Various congenital pathologies may cause upper airway tract obstruction during early childhood ( 1 to 3 years old) such as teratoma, epidermoid, hemangioma, nasal glioma, meningocele, thyroglossal, or meningocele. ${ }^{4,16,17}$ Because the management of these pathologies may be different, HP should be received

May 22, 2014

accepted

July 7, 2014

published online

September 16, 2014
DOI http://dx.doi.org/

10.1055/s-0034-1387812.

ISSN 1809-9777.
Copyright (C) 2015 by Thieme Publicações License terms

Ltda, Rio de Janeiro, Brazil

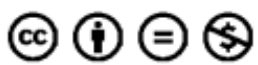


differentially diagnosed with these mentioned diseases. The differential diagnosis of naso-oropharyngeal teratomas should include an encephalocele or meningoencephalocele, as the treatment modalities are totally different. A computed tomography (CT) scan of the head is a reliable and sufficient way to diagnose the presence of an intracranial involvement of encephalocele or meningoencephalocele, and histopathologic examination is required to diagnose hamartomas, teratomas, and HPs. ${ }^{16,17}$

\section{Case Report}

A 3-year-old boy was referred to our department with a lifelong history of occasional pause of breathing while crying. Otorhinolaryngologic examination revealed a pedunculated rubbery mass, originating from the left supratonsillar fossa and extending to nasopharynx (-Fig. 1). The mass moved from the nasopharynx to the orohypopharynx during swallowing and hence caused apnea. Contrast-enhanced CT demonstrated a cystic mass in the nasopharynx, originating from the left lateral oropharyngeal wall, which had a lipoid density. Most probable diagnosis was anticipated to be dermoid cyst. During surgery, following the opening the mouth with a McIvor retractor, the mass was located in the nasopharyngeal region. It looked to originate from both the supratonsillar fossa and the posterior tonsillar pillar. The mass was grabbed and the pedicle was dissected, which was then followed by a total removal using electrodiathermy (-Fig. 2). The upper airway was evaluated for edema, distortion, or hemorrhage particularly in the early postoperative period. Pathologic examination reported a result of "hairy polyp" (-Fig. 3). The postoperative period was uneventful, and no recurrence was noted in the follow-up period of 3 months.

\section{Discussion}

HP symptoms depend on the size and location of the lesion. ${ }^{18}$ The most common symptoms of HP in the oronasopharynx may include rhinorrhea, recurrent cough, failure to gain weight, snoring, and sleep apnea during infancy ${ }^{2-4}$; however, the latter two symptoms, although they might be life-threatening, have rarely been reported in the clinical presenta-

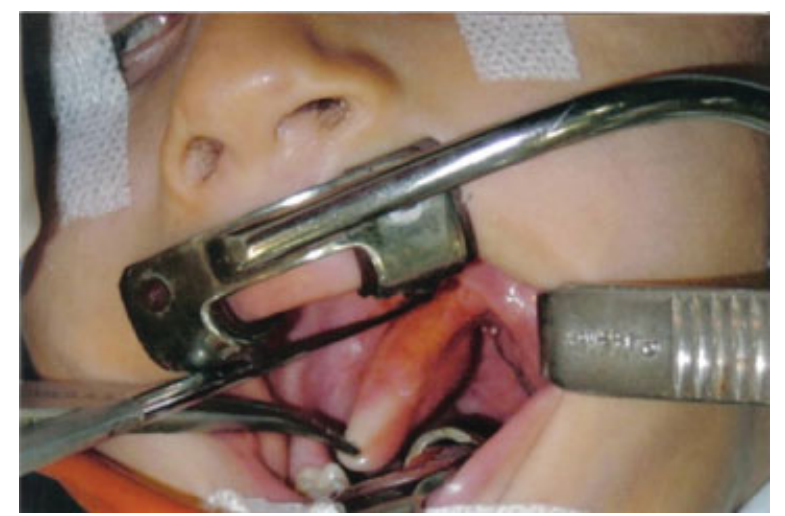

Fig. 1 A pedunculated mass originating from the supratonsillar fossa and posterior tonsillar fold.

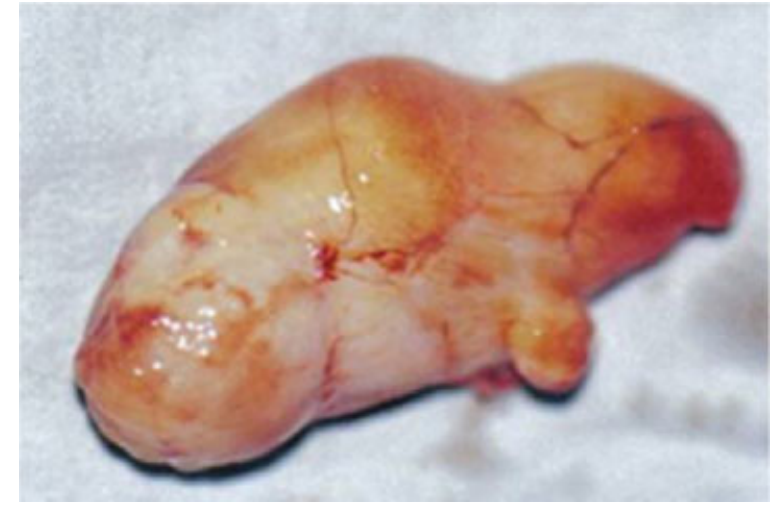

Fig. 2 Totally excised mass.

tions. ${ }^{2-4,14}$ HPs can also cause recurrent purulent otorrhea when the polyp originates from the eustachian tube and affects ventilation of middle ear. ${ }^{9}$ The major complaint of the case presented here was the occasional pausing of breath during crying and thus causing sleep apnea. This may be so serious and urgent that $25 \%$ of the patients might die before being able to surgically intervene. ${ }^{4}$ Therefore, the nasooropharyngeal HP should be removed surgically as soon as possible. As in this case, the respiratory problems completely recovered immediately following surgery, which was followed by the recovery of all other symptoms within the following couple of months.

Most oronasopharyngeal hamartomas are seen in adults. Congenital nasopharyngeal teratomas contain a combination of mature and immature elements of all three germ layers. ${ }^{4,19}$

There is still a debate regarding the etiology of dermoids and HP. There are basically three theories to explain the pathogenesis. According to the totipotential rest theory, DCs (dermoid cysts) arise from totipotent cells derived from ectodermal and mesodermal germinal layers. The congenital inclusion theory proposes inclusion of germinal layers into deeper tissues of fusion lines that have failed to undergo complete closure during embryonic life, leading to trapping of epithelial debris. Acquired implantation theory indicates

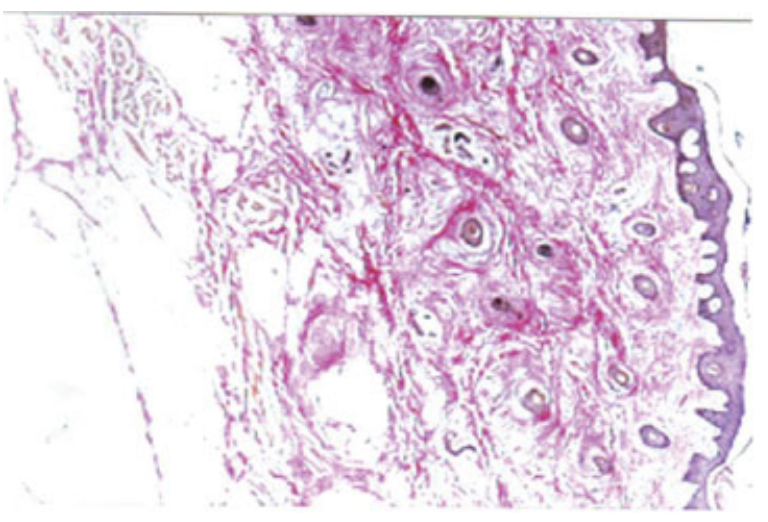

Fig. 3 Histopathologic examination revealed a polypoid mass covered with keratinized stratified squamous epithelium. Pilosebaceous units, hair follicles, fatty tissue, striated and smooth muscle fibers, and connective tissue bundles were observed in the stroma of the polypoid mass. 
traumatic events for the implantation of germinal derivatives into deeper tissues. ${ }^{8,20}$ HPs may be best classified as choristomas. Choristomas contain normal tissue in an anatomically foreign region. ${ }^{18}$ There is no family history of our case. Although there have been some reports about inherited transmission in etiology, definite inheritance has not been clarified. $8,20,21$ HPs are also not associated with congenital syndomes. ${ }^{18}$ Malignant transformation has not been reported for oronasopharyngeal teratoma. ${ }^{22}$

\section{Conclusion}

In conclusion, in a pediatric age group with signs and symptoms of airway obstruction, oropharyngeal HPs must also be included in differential diagnosis.

\section{References}

1 Agrawal N, Kanabar D, Morrison GA. Combined transoral and nasendoscopic resection of an eustachian tube hairy polyp causing neonatal respiratory distress. Am J Otolaryngol 2009;30(5): 343-346

2 Karagama YG, Williams RS, Barclay G, Lancaster JL, Kokai GK. Hairy polyp of the oropharynx in a newborn: a case report. Rhinology 2003;41(1):56-57

3 Kayhan FT, Aydın YZ, Babalioglu M. A nasopharyngeal dermoid causing neonatal airway obstruction. Int J Pediatr Otorhinolaryngol 1997;40(2-3):195-201

4 Roh JL. Transoral endoscopic resection of a nasopharyngeal hairy polyp. Int J Pediatr Otorhinolaryngol 2004;68(8):1087-1090

5 Coppit GL III, Perkins JA, Manning SC. Nasopharyngeal teratomas and dermoids: a review of the literature and case series. Int J Pediatr Otorhinolaryngol 2000;52(3):219-227

6 Tuz M, Dogru H, Uygur K, Baykal B. Rapidly growing sublingual dermoid cyst throughout pregnancy. Am J Otolaryngol 2003; 24(5):334-337

7 Fuchshuber S, Grevers G, Issing WJ. Dermoid cyst of the floor of the mouth-a case report. Eur Arch Otorhinolaryngol 2002;259(2):60-62
8 Görür K, Talas DÜ, Özcan C. An unusual presentation of neck dermoid cyst. Eur Arch Otorhinolaryngol 2005;262(4):353-355

9 Jin L, Zhang T. Surgical treatment of hairy polyp in the eustachian tube. Chin Med J (Engl) 2014;127(5):988-989

10 Uppal HS, D'Souza AR, De R, Irving RM. Dermoid cyst of the infratemporal fossa. J Laryngol Otol 2002;116(2):150-152

11 Guarisco JL. Congenital head and neck masses in infants and children. Part II. Ear Nose Throat J 1991;70(2):75-82

12 White LJ, Shehata BM, Rajan R. Hairy polyp of the anterior nasal cavity. Otolaryngol Head Neck Surg 2013;149(6):961-962

13 Rapidis AD, Angelopoulos AP, Scouteris C. Dermoid cyst of the floor of the mouth. Report of a case. Br J Oral Surg 1981;19(1):43-51

14 Burns BV, Axon PR, Pahade A. "Hairy polyp" of the pharynx in association with an ipsilateral branchial sinus: evidence that the "hairy polyp" is a second branchial arch malformation. J Laryngol Otol 2001;115(2):145-148

15 Bloom D, Carvalho D, Edmonds J, Magit A. Neonatal dermoid cyst of the floor of the mouth extending to the midline neck. Arch Otolaryngol Head Neck Surg 2002;128(1):68-70

16 Pincus RL. Congenital neck masses. In: Bailey BJ, ed. Head \& Neck Surg Otolaryngol. In: Bailey BJ (ed) Head and Neck SurgeryOtolaryngology. Philadelphia, PA: Lippincott Williams \& Wilkins; 2001:932-939

17 Walsh RM, Philip G, Salama NY. Hairy polyp of the oropharynx: an unusual cause of intermittent neonatal airway obstruction. Int J Pediatr Otorhinolaryngol 1996;34(1-2):129-134

18 Lignitz S, Haug V, Siegmund B, Mann WJ, Coerdt W, Mildenberger E. İntermittent dyspnea and cyanosis in a newborn caused by a hairy polyp. Pediatr Neonatol 2014;55(3):231-232

19 Singh RK, Hasan SA, Srivastava RN, Singh PK. Teratoma of the nasopharynx. Ear Nose Throat J 1988;67(9):692-695, 694-695

20 Bratton C, Suskind DL, Thomas T, Kluka EA. Autosomal dominant familial frontonasal dermoid cysts: a mother and her identical twin daughters. Int J Pediatr Otorhinolaryngol 2001;57(3): 249-253

21 Nicollas R, Guelfucci B, Roman S, Triglia JM. Congenital cysts and fistulas of the neck. Int J Pediatr Otorhinolaryngol 2000;55(2): 117-124

22 Cohen AF, Mitsudo S, Ruben RJ. Nasopharyngeal teratoma in the neonate. Int J Pediatr Otorhinolaryngol 1987;14(2-3):187-195 